\title{
Sexual Dimorphism in the Vertebrate Nervous System
}

\section{S. Marc Breedlove}

Department of Psychology and Graduate Group Neurobiology, University of California, Berkeley, California 94720

Many sex differences in the structure of vertebrate nervous systems have been discovered in the past twenty years. The recency of these discoveries is not due to any technological advance; indeed, many of the most interesting of these neural sexual dimorphisms can be detected with nineteenth century methods. Nor can there be much doubt that when the behavior of the sexes differs markedly, there must be sex differences in neural structure mediating those behavioral differences. If previous neuroanatomists assumed that sex differences in brain structure would be too subtle to be detected by current analytical tools, they were proved quite wrong-sex differences appear to be both frequent and prominent features of the nervous system in a wide variety of vertebrates (for surveys of neural sexual dimorphism, see Arnold and Gorski, 1984; Fishman and Breedlove, 1988; Kelley, 1988; De Vries, 1989). In this essay, I discuss progress in the understanding of how these neural sex differences arise, with the twin hopes of identifying those issues that remain unanswered or unaddressed and of convincing readers that the answers to these questions will shed light on the neurosciences beyond the field of sexual differentiation itself.

Steroid hormones play a crucial role in the sexual differentiation of the vertebrate periphery. Whether an individual will develop as a male or female is determined by the parental contribution of sex chromosomes or, for some vertebrates, via environmental stimuli such as incubation temperature (Bull and Vogt, 1979). In either case, the direct consequence of this early, sex-determining event is that the initially indifferent gonads will develop as either testes or ovaries. For example, in male mammals this decision is executed by the testis determination factor (TDF) gene on the Y chromosome. If the TDF gene is expressed by the early, indifferent gonads, then testicular development is induced (Berta et al., 1990). In the absence of TDF function, the gonads develop as ovaries. From that point on, hormonal secretions of the gonad direct whether the rest of the organism, including the brain, develops in a male or female fashion. For mammals, testicular secretions provide active guidance for differentiation as a male, while ovarian secretions may assist but are not necessary for differentiation as a female (Wilson et al., 1981). In other words, in the absence of gonadal secretions, the body, nervous system, and behavior of the animal will develop in a primarily female fashion. The testes, on the other hand, secrete at least two hormones crucial for male development: the peptide Mullerian regression hormone and the androgenic, steroid hormone testosterone (T). Mullerian regression hormone has not been shown to exert any influence on the CNS, but T

$\overline{\text { Copyright (C) } 1992 \text { Society for Neuroscience } 0270-6474 / 92 / 124133-10 \$ 05.00 / 0}$ and its metabolites appear to direct masculinization of all extragonadal tissues, including the nervous system.

\section{Behavioral Studies Predicted Sexual Dimorphism in the CNS}

The effect of perinatal steroid exposure upon later, adult behavior led researchers to predict the presence of steroid-dependent sexual dimorphism in the nervous system long before any cxamples were discovered. These bchavioral studies, analyzing how steroid exposure in development alters adult copulatory behavior patterns and ovulatory physiology, gained wide attention in 1959 with the report from W. C. Young's laboratory (Phoenix et al., 1959) that female guinea pigs exposed to $\mathrm{T}$ before birth were, as adults, sexually unreceptive to males that tried to mount them. Phoenix et al. proposed that androgenic steroids such as $\mathrm{T}$ permanemlly organized the developing brain and that the sex differences in adult behavior reflected that early organization. Later findings made it clear that $\mathrm{T}$ served as a "prohormone" for the masculinization of adult copulatory behavior and ovulatory function in rats. $T$ is converted via aromatization into various estrogens, and these metabolites actually masculinize the brain. Many other behaviors that are displayed more commonly by one sex than the other were subsequently studied, and in each case steroid exposure, usually during a restricted sensitive period in development, could account for the sex differences in adult behavior (for reviews, see Beatty, 1979; Arnold and Breedlove, 1985; Kelley, 1988; Baum et al., 1990).

Frank Beach properly and pointedly reminded behavioral endocrinologists at the time that these sex differences in behavior could result from sexual dimorphism in the periphery and need not involve differences in CNS structure. For example, the degree of masculinization of the body (especially the genitalia) can constrain the degree to which an individual can behave in a male fashion. We will discuss below a recently described affirmation of this principle. Beach went so far as to publish whimsical photomicrographs of an orderly, "organized" female nerve and a tangled, male nerve "disorganized" by early exposure to androgen (Beach, 1971), using longitudinal sections of normal and regenerated amphibian optic nerves for the respective demonstrations. The eventual discovery of steroid-induced neural sexual dimorphism even more striking than Beach's fanciful example laid to rest the question of whether early hormones can alter brain development and amply vindicated the organizational hypothesis. However, the importance of peripheral sex differences for behavioral development has recently resurfaced in modified form. As we will see, in some instances the development of sexual dimorphism in the CNS is in fact a secondary 
response to steroid-induced sexual differentiation of the periphery. Nonetheless, prominent cases of sexual dimorphism in the CNS described in the 1970s and later generated a great deal of interest in tracking down the mechanisms by which steroids alter the developing nervous system.

These robust sex differences in neural structure present a rare opportunity to study neural development precisely because the signals that direct whether the CNS will develop in a malc or female fashion, that is, steroids, have been identified. Therefore, one can systematically manipulate the steroidal signal, detect changes in neural development brought about by the manipulation, and analyze the consequences for future structural and behavioral development. The fact that steroids can directly affect gene expression lends a second advantage to the study of sexual differentiation. Steroid hormones are a large family of lipophilic molecules that allosterically bind to specific protein receptors (which are themselves part of a superfamily of DNAbinding molecules). The steroid-receptor complex then interacts with DNA to alter transcription of a specific, albeit potentially large subset of the genome (Beato, 1989). Therefore, when experimenters manipulate steroid levels and set off a cascade of events that alter development, they can, in theory, trace the molecular beginnings of that cascade to those genes that initially responded to the steroid.'

I will briefly describe below several vertebrate neural systems that display prominent sexual dimorphism that, true to the organizational hypothesis, results from steroid hormone action. Researchers in this field are, de facto, systematically completing a program for a satisfactory understanding of the molecular, cellular, and behavioral consequences of an early developmental choice point, that is, whether to develop in a male or female fashion.

For each identified instance of sexual dimorphism, researchers attempt to determine (1) which of the various steroids guide masculinization of the identified sexual dimorphism (i.e., whether $\mathrm{T}$ itself or its estrogenic metabolites are effective), (2) the sensitive period during which the steroid can masculinize the system, (3) which cellular process(es) is affected by steroid exposure (i.e., whether cell division, differentiation, migration, death, etc., are altered), (4) which cell population first responds to the steroid to initiate that masculinizing process, (5) which gene(s) are regulated by steroid in that identified cell population, (6) whether the altered expression of those genes is in fact responsible for the altered cellular process, (7) the behavioral consequences of the alteration in neural structure, and finally, (8) whether environmental/experiential factors modulate the effects of hormones during sexual differentiation of the model system. To date there has been considerable progress in answering the first two questions and glimmers of answers to questions 3 and 4 in a few systems, but for no system have questions 5 or 6 been fully answered. However, the technology to address those latter questions is relatively recent and there is reason to believe that they can be resolved in the not-too-distant future. Some of the

\footnotetext{
'The reader should be warned that there are also a growing number of cases where steroids appear to have an alternative, nongenomic mechanism of action. Specifically, some steroidal effects appear to be too rapid to reasonably involve changes in gene expression, additional steroid receptors seem to be restricted to cell membranes, and steroids can alter channels in isolated membrane patches (e.g., Kelly et al., 1977; Erulkar and Wetzel, 1989; Schumacher et al., 1990; Delville, 1991; Orchinik et al., 1991). However, because none of these mechanisms have yet been implicated in sexual differentiation, and because nuclear steroid receptors are crucially involved in at least some animal models, this essay considers steroids in their more orthodox role as gene regulators (Wahli and Martinez, 1991).
}

most interesting recent results concern the last question, that is, whether experience can modulate the effects of steroids, and I will describe those reports in some detail after describing the various models and progress concerning molecular events. Finally, I will try to relate this information to reports of sexual dimorphism in the human nervous system.

\section{Prominent Models of Neural Sexual Dimorphism}

\section{Songbird vocal control regions}

Although there were several previous reports of reliable yet subtle sex differences in neural structure (e.g., Pfaff, 1966; Raisman and Field, 1973), Nottebohm and Amold (1976) surprised many scientists with the announcement that parts of the songbird brain are five to six times larger in volume in males than in females. Further work found that the individual neurons in these regions are larger and have a greater dendritic extent in males than in females (DeVoogd and Nottebohm, 1981). Since these brain regions were known to be involved in the production of courtship song (Nottebohm et al., 1976), and since males sing more than do females in the species examined (zebra finches and canaries), the sexual dimorphism in neural structure seemed clearly related to sex differences in behavior. These same vocal control regions (VCRs) are nearly monomorphic in species in which both sexes sing (Brenowitz et al., 1985), which strengthens the idea that the volume of these nuclei is at least grossly related to vocal behavior capacity.

How does sexual dimorphism in VCR arise? As with other extragonadal tissues, sexual differentiation of the brain of songbirds is directed by early steroid signals. Young female zebra finches treated with the estrogen estradiol (E2) upon hatching will sing when given androgen in adulthood (Gurney and Konishi, 1980; Gurney, 1981; Konishi, 1989). The VCRs of these singing females are larger than those of normal females and rival those of males. The finding that an estrogen was as effective as $\mathrm{T}$ and more effective than another androgen (i.e., dihydrotestosterone; Schlinger and Arnold, 1991 a) at masculinizing young female zebra finches was not too surprising, because previous work had established that $\mathrm{T}$ can be converted to $\mathrm{E} 2$ in brain tissues (see Naftolin and MacLusky, 1984, for review) and such a conversion is a normal part of the process by which perinatal T masculinizes several adult behaviors in rats (e.g., Whalen and Nadler, 1963; Hendricks and Gerall, 1970; Christensen and Gorski, 1978). One might presume that the gonads provide the $\mathrm{T}$ and, ultimately, estrogen for normal males, but no one has yet managed to prevent masculinization of male zebra finches by early castration. In fact, the brain may be the primary source of circulating estrogens in zebra finches, since the enzyme required for estrogen formation (aromatase) is highly active throughout the telencephalon of this species (Schlinger and Arnold, 1991b).

How do early steroids masculinize VCR development? One of the forebrain VCR, the robust nucleus of the archistriatum (RA), goes through a period of ontogenetic cell death that is more pronounced in females than in males (Konishi and Akutagawa, 1985). Thus, steroids apparently ameliorate cell death in this nucleus to engender the sex difference in volume. Interestingly, another VCR, hyperstriatum ventrale caudale (or higher vocal center; $\mathrm{HVc}$ ), which projects to RA in adulthood, may modulate the extent of cell death and hence the masculinization of RA. Before RA has become sexually dimorphic, that is, before cell death has commenced, HVc afferents have arrived at the periphery of RA, but have not yet invaded and fully innervated 
the cells there (Konishi and Akutagawa, 1985). Because the eventual ingrowth of HVc fibers into RA coincides with the onset of cell death, it is possible that the afferents, either by dint of their numbers, activity, or trophic support, might regulate cell death in RA and therefore its sexual differentiation. Indeed, lesions of $\mathrm{HVc}$ seem to diminish the effectiveness with which steroids masculinize RA and area X (Herrmann and Arnold, 1991), another VCR that receives projections from HVc. The finding that some $\mathrm{HVc}$ neurons contain estrogen receptors at an earlier stage than do cells in RA or area X (Gahr and Konishi, 1988 ) is also consistent with this hypothesis. However, even in $\mathrm{HVc}$, the number of cells containing estrogen receptors is quite small (Nordeen et al., 1987), and no one has demonstrated that estrogen actually acts upon $\mathrm{HV}_{\mathrm{c}}$ to masculinize any VCR, including IIVc itself. Thus, a competing hypothcsis is that RA itself may normally respond to the estrogen, but can only do so when properly innervated. There is also sexual dimorphism in the vocal organ of songbirds (the syrinx) and in the XII nucleus motoneurons controlling muscles of the syrinx (Nottebohm and Arnold, 1976; Gurney, 1982), but the question of whether steroids act directly upon the vocal apparatus and/or nucleus XII to induce their dimorphism has not yet been addressed.

Canaries offer unique opportunities to study the effect of steroids on CNS structure because, unlike zebra finches, male canaries learn additional songs through their lifetime. This behavioral plasticity is mirrored by the structure of VCR: dendritic complexity (DeVoogd and Nottebohm, 1981), VCR volume in Nissl-stained material (Nottebohm, 1981), and song repertoire all wax and wane with circulating androgens in this seasonally breeding species (Nottebohm et al., 1990). This plasticity is apparent in female canaries, too, since $T$ treatment in adulthood can induce females to sing and concomitantly enlarges VCR volume. Thus, unlike zebra finches, which must be exposed to gonadal steroids early in life to produce song later, canaries seem susceptible to the masculinizing influence of steroids throughout life. However, recent work suggests a slight reinterpretation of the seasonal fluctuations in VCR volume. When HRP is injected into RA, projection neurons from throughout $\mathrm{HVc}$ are labeled. The volume of $\mathrm{HVc}$ as defined by these labeled projection neurons does not change with adult androgen treatment, even though alternate, Nissl-stained sections confirm the originally reported change in volume (Gahr, 1990). There is a similar discrepancy in the size of the magnocellular nucleus of the anterior neostriatum when measured in Nissl stain versus the distribution of projection neurons (Nordeen et al., 1992). Thus, the previous reports of volume changes with hormone status may reflect alterations in the Nissl-staining characteristics of the periphery of $\mathrm{HVc}$ rather than a uniform expansion of the entire nucleus. The functional significance of the changes in Nissl-stained material remains unknown, but the many correlations between $\mathrm{HVc} / \mathrm{RA}$ volume and singing behavior remain compelling (Bottjer et al., 1986; Bottjer and Dignan, 1988).

The discovery that new neurons arise from dividing precursors in the ventricular zone of adult canaries (Goldman and Nottebohm, 1983), and that the electrical activity of at least some of these new neurons is sensitive to auditory stimuli (Paton and Nottebohm, 1984), opened the possibility that steroids might direct sexual differentiation in developing zebra finches or adult canaries by regulating neurogenesis. Indeed, estrogen treatment during adolescence increases the number of newly synthesized neurons found in HVc of zebra finches (Nordeen and Nordeen, 1989), and at least some of these new neurons project to RA
(Alvarez-Buylla et al., 1988; Nordeen and Nordeen, 1988; Konishi and Akutagawa, 1990). However, the links between steroids, neurogenesis, and song learning remain tentative. First, it is difficult to distinguish changes in the rate of neurogenesis from changes in the differentiation or death of newly dividing cells. Second, modest amounts of neurogenesis also occur in the VCR of untreated adult female canaries and zebra finches (which do not sing) and in adult male zebra finches (where song seems unchanged). Third, the seasonal fluctuations in male canary VCR dendritic structure, volume, and singing, processes driven by seasonal testicular production of $\mathrm{T}$, are not accompanied by any striking seasonality in overall neurogenesis (Alvarez-Buylla et al., 1988), although there appear to be seasonal differences in the production of projection neurons in HVc (Kirn and Nottcbohm, 1991). Nottcbohm (1991) has suggested that neurogenesis could reflect changes in song perception rather than production (Brenowitz, 1991).

\section{Frog vocalization system}

Male African clawed frogs produce a courtship song that female frogs do not, in part because the female larynx is smaller and has fewer and smaller muscle fibers than the male larynx. Androgen induces this dimorphism by potentiating myogenesis and chondrogenesis in the larynx of juvenile males (Sassoon et al., 1986). It is not known whether these tissues themselves respond to androgen or are altered by steroid action upon some intermediary tissue(s). The laryngeal muscle fibers are predominantly of the slow twitch type in females and entirely of the fast twitch type in males (Sassoon et al., 1987). That this peripheral sexual dimorphism constrains the vocal behavior of the two sexes can be demonstrated by in vitro preparations where stimulation of the nerves can produce sounds with spectral properties identical to male-like mate calling from isolated male but not female larynges (Tobias and Kelley, 1987). Chronic androgen treatment of adult females can partially masculinize laryngeal structure and in vitro function, but early testicular grafts are required to masculinize completely the larynx and singing of females (Watson and Kelley, 1991). Thus, Beach's (1971) suggestion that peripheral sex differences could contribute to sex differences in behavior is supported. However, there is also a sex difference in the number of brainstem motoneurons in nuclei IX and $\mathrm{X}$ (which innervate the larynx), and because a sex difference in the number of axons innervating the larynx precedes any detectable sex difference in laryngeal structure (Kelley and Dennison, 1990), it seems likely that steroids also directly masculinize CNS development to alter behavior in this case. As we shall see, the Xenopus vocalization system appears particularly suited for studies of the molecular events underlying sexual differentiation (Fischer and Kelley, 1991).

\section{Rat perineal muscles}

Both male and female rats are born with bulbocavernosus (BC) and levator ani (LA) muscles attached to the base of the penis or clitoris, respectively. In both sexes, the muscles are innervated at birth by cells in the spinal nucleus of the bulbocavernosus (SNB) (Sengelaub and Arnold, 1986; Rand and Breedlove, 1987). However, around the time of birth, the BC/LA muscles in females atrophy completely (Hayes, 1965; Cihak et al., 1970) or almost completely (Tobin and Joubert, 1991), and far more SNB cells are lost in females than in males (Nordeen et al., 1985; Breedlove, 1986), resulting in sexual dimorphism in adulthood (Breedlove and Arnold, 1980). T treatment preserves the BC/ 
LA and SNB cells in developing females, while pharmacological blockade of androgen and castration causes their demise in perinatal males (Breedlove and Arnold, 1983a,b). If hormone treatment is begun after motoneuronal death is complete, the number of SNB cells is unaffected. Further evidence that androgen receptors are required for the sparing of this system comes from male testicular feminization mutant $(T f m)$ rats that, because of a single base pair substitution in the structural gene for the androgen receptor (Yarbrough et al., 1990), are insensitive to androgen and develop a female SNB system (Breedlove and Arnold, 1981).

Androgen acts directly upon the $\mathrm{BC} / \mathrm{LA}$ muscles to prevent their atrophy, and sparing of SNB motoneurons is a secondary consequence of that effect. Studies of Fishman and Breedlove (1985) eliminated the possibility that supraspinal afferents modulated the effect of androgen on SNB survival, or that SNB survival was necessary for androgenic sparing of the $\mathrm{BC} / \mathrm{LA}$ (Fishman and Breedlove, 1988). The BC/LA muscles can bind androgen around the time of birth, but the SNB motoneurons do not (Fishman et al., 1990; Jordan et al., 1991). Finally, T-induced preservation of SNB motoneurons can be blocked most effectively by pharmacological interference with androgen binding in the muscle (Fishman and Breedlove, 1987). Thus, in this case, sexual differentiation of the periphery directs sexual differentiation of the CNS.

Cynthia Jordan and colleagues have shown that the androgen sensitivity of the LA in male rats continues past the perinatal period and into prepubertal ages. Circulating androgen levels are normally low during this phase, but $\mathrm{T}$ treatment begun on postnatal day 7 (P7) alters the course of neuromuscular synapse elimination, that is, the transition from primarily multiple innervation to single innervation of muscle fibers (Jordan et al., 1989). By P28, the LA in normal males is primarily (i.e., 70\% of fibers) singly innervated, whereas in the LA of castrates given 3 weeks of T, only $30 \%$ of the muscle fibers have become singly innervated. Since the effect of androgen manipulation is accompanied by changes in motor unit size, it seems likely that synapse elimination per se is altered by steroids in this system (Jordan et al., 1992). The effect of androgen on synapse elimination seems to be permanent, since multiple innervation is maintained a year after $\mathrm{T}$ treatment has ended (Lubischer et al., 1992). Still unknown is whether T exerts these effects on synapse elimination via androgen or estrogen receptors, and whether motoneurons or muscles are the site of steroid action for these effects.

\section{Sexually dimorphic nucleus of the preoptic area}

Shortly after the discovery of gross sexual dimorphism in the brains of songbirds, Roger Gorski and colleagues discovered a prominent sexually dimorphic nucleus within exactly that part of the rat brain that had been most persuasively implicated in sexual function - the preoptic area (POA). The nucleus, christened the sexually dimorphic nucleus of the preoptic area (SDNPOA), was five to six times larger in volume in male than in female rats (Gorski et al., 1978). The adult volume of the SDNPOA can be manipulated by altering androgen levels just before or just after birth, but not by androgen manipulations in adulthood. Because the period of neurogenesis in the SDN-POA (Jacobson and Gorski, 1981) coincides with the fetal period of T secretion (Warren et al., 1973), and because there are sex differences (favoring males) in the number of radiolabeled neurons in the adult SDN-POA following late fetal injections of tritiated thymidine (Jacobson and Gorski, 1981), androgens may augment neurogenesis in this region. As shown for copulatory behaviors in rodents previously, sexual differentiation of SDNPOA morphology is sensitive to estrogenic metabolites of $T$ rather than to androgens per se (Dohler et al., 1982). This inference is bolstered by the finding that $T \mathrm{fm}$ rats that have defects in androgen but not estrogen receptors (Yarbrough et al., 1990) have a male SDN-POA (Jacobson, 1980). Because affected Tfm males have a female exterior, the male nature of the SDN-POA in $T f m$ rats also indicates that steroids act centrally rather than peripherally to direct the development of this nucleus. The pattern of serotonergic innervation in the developing POA suggests that these afferent fibers may play a role in sexual differentiation of the SDN region (Simerly et al., 1984; Handa et al., 1986), but that hypothesis is untested. Thus, the primary site of steroid action for the masculinization of the SDN-POA remains unknown. Neither is the behavioral function of the SDN-POA clearly established. Lesions of the entire POA in rats (and monkeys and many other vertebrates; Hart and Leedy, 1985) severely reduce male copulatory behavior, but lesioning of the $S D N$ portion of the POA in rats has been reported to result in either no change in male or female sexual behavior (Arendash and Gorski, 1983), or only a slight and temporary deficit in male copulatory behavior (De Jonge et al., 1989). Both of these studies agree that male rats without an intact SDN-POA can and will copulate in an apparently normal fashion.

\section{Why Do Steroids Alter So Many Developmental Processes?}

So far we have listed instances where steroids appear to alter neurogenesis (Nordeen and Nordeen, 1989), synapse elimination (Jordan et al., 1989), cell death (Konishi and Akutagawa, 1985; Nordeen et al., 1985; Breedlove, 1986), and dendritic extent (DeVoogd and Nottebohm, 1981; Forger and Breedlove, 1987b). In other systems, steroids apparently alter the rate of axonal outgrowth (Yu \& Srinivasan, 1981), subsequent steroid sensitivity (Breedlove, 1983), neurotransmitter expression (De Vries, 1989), and cell migration (Breedlove, 1985; Sengelaub and Arnold, 1986). I suspect the main reason steroids have not bccn shown to affect the differentiation of cells into neurons is because such effects are generally difficult to document in vivo. That steroids alter so many cellular processes suggests that sexual differentiation of nervous system development is rather prevalent among vertebrates. One can only speculate that natural selection and sexual selection have favored different behaviors in the two sexes. The existence of a fairly unitary signal for gender (i.e., steroids) may have promoted or allowed such differential selection, since sex differences in neural structure require only that androgen modulate the expression of genes already directing development in both sexes. Regardless of how such a wide variety of processes came to be steroid sensitive, that sensitivity offers an excellent opportunity to perturb different developmental processes experimentally and monitor the consequences.

\section{Which Genes Do Steroids Regulate to Direct Sexual Differentiation?}

It seems clear that the alteration of cell fate during sexual differentiation, for example, whether the cells die, extend dendrites, retract axon collaterals, have large or small somata, or undergo a secondary migration, will be accompanied by changes in gene expression. The first challenge, as we have seen, is determining 
which cell population is responding to the steroid. Then one can search for those genes that are regulated by the steroid. ${ }^{2}$

Relatively few studies have tried to correlate steroid-induced alterations in gene expression with changes in neural fate, and for practical reasons, the first attempts have focused on systems in which a peripheral component (e.g., muscle) can be readily isolated. We know that in the SNB neuromuscular system, androgen acts directly upon the $\mathrm{BC} / \mathrm{LA}$ muscles to prevent their atrophy and secondarily spare SNB motoneurons. When newly synthesized muscle proteins from the BC/LA of newborn rats were separated by two-dimensional gel electrophoresis, males and females were found to make approximately equal levels of each of some 200 discriminable proteins. However, one protein, later identified as myosin light chain 1 (LC1), was prominent in the gels from BC/LA of newborn males but was not detectable in gels derived from females (Forger et al., 1991). Androgen treatment at least $96 \mathrm{hr}$ prior to death induced production of $\mathrm{LC} 1$ in the BC/LA of females. Nonetheless, the female BC/LA must have synthesized LCl sometime before birth, because the muscles contain LCl detectable by immunocytochemistry. The extended lag between androgen treatment and newly synthesized $\mathrm{LC} 1$ indicates that $\mathrm{LCl}$ expression is not a primary response to androgen, and the immunocytochemistry indicates that $\mathrm{LCl}$ is not responsible for the differential fate of the $\mathrm{BC} / \mathrm{LA}$ in the two sexes. Nonetheless, the apparent cessation of LC1 production in doomed female BC/LA may be an early molecular marker of the involution of these muscles.

In the frog vocalization system, newly available molecular probes have revealed that androgen receptor mRNA transcripts are found in brainstem neurons at early stages before steroid accumulation over their nuclei can be demonstrated. Second, the larynx appears to express a second, shorter transcript for the androgen receptor and may be the only tissue to do so (Fischer and Kelley, 1991). Such a tissue-specific transcript may serve to regulate a unique subset of genes to masculinize the larynx. Finally, androgen can repress the transcription of the gene encoding its own receptor in the frog larynx, in apparent analogy to androgenic repression of receptor gene transcription in mammalian prostate (Quarmby et al., 1990). Because androgen also induccs laryngeal muscle fibers to change from the slow to the fast twitch type (Sassoon et al., 1987), the androgenic regulation of isozymes underlying that change should be amenable to future study.

\section{Exogenous Influences upon Sexual Differentiation among Nonhuman Animals}

That sex steroids exert a robust influence on such a wide variety of cellular processes does not rule out the possibility that environmental stimuli can also affect sexual differentiation. Indeed, although fetal androgen levels are usually a fairly direct result of the individual's genome (i.e., whether they possess the gene for TDF and therefore develop testes), steroids from one individual can sometimes provide an exogenous influence on anothcr. Whether or not a female calf born with a male twin will be sterile in adulthood depends on how closely the placentas of the two calves were adjoined (Lillie, 1916). Similarly, the presence of adjacent male fetuses in utero can affect the later sexual behavior of female rodents (Clemens et al., 1978; vom

\footnotetext{
${ }^{2}$ A subsequent concern would be whether steroids directly or indirectly affect expression of the gene. For example, the steroid-receptor complex may interact directly with the promoter region of the identificd genc, or affect expression of another, "upstream" gene, the product of which alters expression of the identified gene.
}

Saal, 1979; Meisel and Ward, 1981), apparently because T from male fetuses can reach and affect neighboring female fetuses. Thus, circumstances that alter exposure to one's own androgen supply, or that of others, can affect sexual differentiation.

One exogenous influence upon $T$ secretion, and therefore the extent of sexual dimorphism, has been studied by Ingeborg Ward and her colleagues. They found that exposing pregnant rat dams to stressful conditions (restraint under bright lights several times per day) caused their fetal offspring to produce less gonadotropin and therefore less androgen (Ward and Weisz, 1980). The reduction in endogenous androgen during the fetal period results in a smaller SDN-POA (Anderson et al., 1985) and fewer surviving SNB motoneurons in adulthood than in rats not prenatally stressed (Grisham et al., 1991). This same prenatal stress also alters the adult sexual bchavior of rats, but the extent of behavioral impairments can be dissociated from either SDNPOA volume or SNB number, indicating that the prenatal androgen deficit has neural effects beyond these systems (Grisham et al., 1991).

Celia Moore and colleagues have presented a demonstration that experience can alter the structure of sexually dimorphic neural regions. Rat dams aid reflex evacuation in pups by licking the anogenital region of both male and female pups, but spend more time licking males than females. The dam directs extra attention to pups that have endogenously or exogenously supplied androgen, probably by detecting T metabolites in the pups' urine. Dams made temporarily anosmic spend less than half as much time licking the anogenital region of pups (of either sex), but provide otherwise apparently normal maternal behavior. Male pups reared by anosmic dams have, as adults, significantly fewer SNB motoneurons than do normal rats (Moore et al., 1992). The most plausible hypothesis is that the sensory stimulation activates afferent signals that reach the developing motoneurons and help spare them from ontogenetic death (Okado and Oppenheim, 1984). While the difference amounts to only $11 \%$ fewer motoneurons in the SNB, a change of this magnitude in the face of a known, profound influence of androgen demonstrates that even powerful biological signals can have their effects modulated by experience. Another scenario points out the possibility of iterative interactions between hormones and experience. Because the pups in Moore's study were gonadally intact, it is possible that anogenital stimulation promotes further androgen release from the testes (Bernstein et al., 1983). Moore has not yet determined whether anogenital stimulation is effective in gonadectomized animals or whether the structure of the SDN-POA is also affected by such stimulation. Finally, there are subtle but reliable sex differences in the dendritic structure of cortical neurons and in the axonal composition of the corpus callosum in rats (Juraska, 1990). Interestingly, several of these sex differences are seen only when animals are raised after weaning in so-called enriched conditions, that is, social housing in large cages provided with toys. The sex differences do not appear when the animals are raised in more standard, isolated conditions, perhaps because male and female rats have more nearly identical experiences in such conditions. This possibility that males and females have different brains in adulthood because they seek out different experiences during development is a prominent issue concerning sexual differentiation in humans.

\section{Neural Sexual Differentiation among Humans}

The most pressing question concerning sexual differentiation of the nervous system in humans is no longer whether there are 
scxually dimorphic neural regions-clearly there are. The unanswered question of concern to many people is whether the sexual dimorphism found in the human nervous system is the result of sex differences in early hormonal stimulation, and therefore a primarily biological phenomenon, or the result of differences in early experience, and therefore a primarily social phenomenon. This is a difficult distinction to draw when experimentation is not possible and purely descriptive studies must be relied upon. Furthermore, as we have just noted, experience can alter the response to an endogenous hormone. Thus, to date, neither early hormones nor early experience have been conclusively shown to affect sexual differentiation of neural morphology in humans.

A sex difference in the weight of the human brain was first reported in 1880 (see Swaab and Hofman, 1984, for review), and this difference is roughly proportional to sex differences in height. The sex difference in brain weight may be present at birth, but it is quite small (e.g., 5\%) and does not peak until 9 years of age (Dekaban and Sadowsky, 1978). Whether brain volume is determined by body volume (Purves, 1988), body volume determined by brain volume, or each independently affected by some other factor (e.g., growth hormone) is not known, but a difference present at birth, before anyone knows the sex of the child, cannot be the result of social influences. In fact, a sex difference in brain volume represents the only sex dimorphism in the human CNS that can be comfortably attributed to nonsocial factors, presumably prenatal androgens. There have also been several conflicting reports about sexual dimorphism in the midsagittal profile of the corpus callosum in humans (deLacoste-Utamsing and Holloway, 1982; Witelson, 1985; Oppenheim et al., 1987). One recent report, based upon magnetic resonance imaging of the corpus callosum (Allen et al., 1991), finds no sex difference in total midsagittal area, but a difference in the shape of the structure such that women have a more bulbous splenium (the caudal portion of the corpus callosum) than do men. Because this report is consonant with the original finding (deLacoste-Utamsing and Holloway, 1982), and because Allen et al. could find the sex difference only by following that original, rather complicated measurement protocol, the final word on the controversy may be that there is a very subtle sex difference in the shape rather than the size of the corpus callosum. The report that this sexual dimorphism is present in fetal material (deLacoste et al., 1986) has not, to my knowledge, been replicated. For example, Allen et al. did not find a significant sex difference in the corpus callosum of children. Even if they had found such a difference, the age range examined (2-16 years) leaves ample room for social influences to have played a role (Allen et al., 1991). There are also several reports of sex differences in the symmetry of the human brain (Crichton-Brown, 1880; Wada et al., 1975). It has been suggested that these asymmetries and/or a sex difference in the corpus callosum connecting the two hemispheres may be related to rather subtle sex differences in the lateralization of cognitive function (McGlone, 1980; Kimura and Harshman, 1984). There is also the report that women exposed in utero to the powerful estrogen diethylstilbestrol (DES) were, as adults, morc latcralizcd (i.c., more male-like) on such tests than their non-DES-exposed sisters (Hines, 1982). Whether the brains of these DES-exposed women are more male-like in terms of cortical or callosal structure has not been addressed.

Onuf's nucleus, the human homolog to the rat SNB, that is, the source of motoneurons innervating the $\mathrm{BC}$, has more mo- toncurons in men than in women (Forger and Brcedlove, 1986). Because the fetal period of spinal motoneuron death in humans (Forger and Breedlove, 1987a) overlaps the period of testicular secretion in males (Siiteri and Wilson, 1974), this sexual dimorphism in humans may arise in much the same way as in the SNB of rats, that is, by androgen altering muscle fate and thereby sparing motoneurons from ontogenetic death.

Swaab and Fliers (1985) first reported a sexually dimorphic nucleus in the POA of humans. They named this nucleus the SDN-POA because it roughly resembled that nucleus in rats and, as in rats, was larger in males than in females. Roger Gorski and colleagues later examined the human POA and subdivided its nuclei into four groups: the interstitial nuclei of the anterior hypothalamus (INAH)-1-4 (Allen et al., 1989). Allen et al. reported that what had been termed the human SDN-POA (Swaab and Fliers, 1985) is equivalent to their INAH-1, but they found no sex difference in INAH-1 volume (Allen et al., 1989). Rather, they reported that INAH-2 and INAH-3 were larger in men than in women. This scene was further complicated by Simon LeVay's (1991) later report of a sexual dimorphism in INAH-3 but not INAH-2 (nor INAH-1, Swaab and Fliers' SDN-POA). Differences in the age ranges of subjects in these various studies may account for these discrepancies, but it also seems clear that any sexual dimorphism in the POA is more subtle in humans than in rats, and underscores the importance of large, representative samples and replications for such studies.

The primary interest in LeVay's report concerned the finding that INAH-3 is not only smaller in women than in men, but is also smaller in homosexual men than in heterosexual men (LeVay, 1991). Several possible confounding variables (such as contraction of AIDS, brain size, body size, age, etc.) could not explain the differences found in INAH-3. Because lesions of the entire POA seem to abolish the interest of male monkeys in mounting females, without abolishing their interest in masturbation (Slimp et al., 1975), the POA had been proposed as the neural region directing males to seek females as sexual partners. Extending this idea, Le Vay hypothesized that because homosexual and heterosexual men differ in their sexual interest in females, they might also differ in some characteristic of the POA. Not all the animal data support this scenario. Monkeys with a lesioned POA do not reverse their sexual preference to males; they simply do not approach females. Furthermore, as mentioned above, lesions of the $S D N$ portion of the POA in rats has very little (De Jonge et al., 1989) or no effect (Arendash and Gorski, 1983) on either the performance or latency of males to copulate, and no one has attempted to determine whether such lesions affect sexual preferences in rats, nor has anyone lesioned subregions of the POA in primates. The report of a positive correlation between the volume of the SDN-POA and male copulatory performance in either prenatally stressed or control male rats (Anderson et al., 1986) has been used to support the role of the SDN-POA in male copulatory behavior. However, in this report on gonadally intact animals, plasma $\mathrm{T}$ levels were positively correlated with both morphological and behavioral measures (Anderson et al., 1986). Thus, individual differences in $T$ production could have independently affected the SDNPOA and other, quite separate, neural centers regulating copulatory behavior.

Le Vay's report has revived debates of whether sexual orientation in humans is "biological" or "social," by which is meant whether biological or social influences are primarily responsible for the direction of sexual interest. Of course, the 
existence of a biological influence on sexuality does not preclude the existence of other, social influences, or vice versa. There must be some environmental influence upon human sexuality, since monozygotic twins do not always have the same sexual orientation (for recent discussions, see Bailey and Pillard, 1991; Buhrich et al., 1991). Indeed, as discussed above, one of the ways hormones can affect sexual differentiation in rats is by altering the social interest of others (e.g., the dam detecting androgen in the urine) in that individual. Conversely, social influences, such as stressful experience, can alter the hormonal secretions of rats, and during development, that can affect the course of sexual differentiation. If hormones and experience are so routinely tangled even in rats, surely one may expect such interactions in humans. This failure to distinguish between a morphological correlate of homosexuality and a biological cause of homosexuality is found in the reactions to LeVay's report (Tuller, 1991). LeVay expressly acknowledges the possibility that a smaller volume in INAH-3 could be the result rather than the cause of homosexual development, or could even be the result of adult homosexual experiences. In fact, even if social factors were entirely responsible for the development of sexual orientation, one might expect that some parts of the brain would be different in heterosexual and homosexual men. That such differences would be amenable to detection by current methods is perhaps no more surprising than the detection of differences between the sexes in neural structure. The common self-report that earliest memories of erotic interest match adult sexual orientation has been used to assert that some people are "born gay" (Tuller, 1991), but such logic could equally support the notion that some are born to speak English rather than Russian. In both cases, it is clear that social influences on the behavior in question may predate the individual's memory.

\section{Future Challenges in the Study of Neural Sexual Dimorphism}

The current enthusiasm for molecular studies of neural development will likely extend to the molecular basis of sexual differentiation, and such data will be required for a complete understanding of the process. However, cellular studies must first lay the groundwork for molecular approaches, since one must know which cell population is responding to the steroid before assessing which genes have been crucially regulated there. Thus far, we know little about the primary site of steroid action for any of the models of sexual dimorphism. There is reasonable evidence that for the SNB, androgens act upon some cells within the target muscle, and that the decision of whether an SNB motoneuron will die is not affected by androgen interaction with the motoneuron itself. Thus, direct steroidal alterations in gene expression by the target muscle may be relevant to the survival of muscle fibers and motoneurons. It is not clear which cells are the primary site of steroid action for differentiation of the other neural dimorphisms. Indeed, there is as yet no demonstration that steroids act directly upon the genome of any neuron in vivo. In some brain regions a scant minority of neurons contain steroid receptors, and in those same regions the morphology of some neurons is altered by steroid manipulation, but no one has demonstrated that a neuron that possesses steroid receptors also shows a morphological response to the steroid. A conclusive demonstration that such a correlation was the result of direct action of steroid within that neuron will require comparing neurons that are alike in every respect except for the presence of functional receptors.
Another future challenge will be a better understanding of factors that determine whether a cell will produce a particular steroid receptor and, if so, which of many possible changes the cell will undergo when the steroid-receptor complex is activated. There are several instances of steroid levels in adulthood influencing the extent to which receptors are expressed in various tissues, and such influences can explain many sex differences in steroid receptor content in the CNS (Breedlove, 1983). However, we have no idea why, for example, spinal motoneurons express androgen and glucocorticoid receptors but not estrogen receptors (Sar and Stumpf, 1977; Simerly et al., 1990), and progress in answering such questions will probably come from molecular studies of steroid-sensitive cell lines (e.g., Yamamoto, 1985). Progress concerning the specificity of response to steroid must also await molecular studies. The finding that the DNA sequence sought out by steroid-receptor complexes, the "hormone response element," is much the same for different steroids (Beato, 1989), despite the very different responses cells make to those different hormones, indicates that cofactors and differential gene access may determine the specifity of cell response.

Finally, the challenge remains to catalog in any one vertebrate system the genes that directly respond to steroid, the immediate and the indirect consequences of that response for the expression of uther genes, the alterations in cellular morphology and function engendered by those changes in gene expression, and the sex differences in behavior resulting from that sexual dimorphism. This agenda will be especially difficult and controversial when applied to humans, not only because of the practical and ethical limitations of working with our species, but also because animal models are already pointing out that experience can modify the extent of sexual dimorphism, even in systems that are very sensitive to early steroid action. We may expect the highly social human species to show at least as much sensitivity to environmental modulation, and that will make demonstration of any hormonally orchestrated sexual dimorphism in the nervous system much more difficult.

\section{References}

Allen LS, Hines M, Shryne JE, Gorski RA (1989) Two sexually dimorphic cell groups in the human brain. J Neurosci 9:497-506.

Allen LS, Richey MF, Chai YM, Gorski RA (1991) Sex differences in the corpus callosum of the living human being. J Neurosci 11:933942.

Alvarez-Buylla A, Theelen M, Nottebohm F (1988) Birth of projection neurons in the higher vocal center of the canary forebrain before, during and after song learning. Proc Natl Acad Sci USA 85:87228726.

Anderson DK, Rhees RW, Fleming DE (1985) Effects of prenatal stress on differentiation of the sexually dimorphic nucleus of the preoptic area (SDN-POA) of the rat brain. Brain Res 332:113-118.

Anderson RH, Fleming DE, Rhees RW, Kinghorn E (1986) Relationships between sexual activity, plasma testosterone, and the volume of the sexually dimorphic nucleus of the preoptic area in prenatally stressed and non-stressed rats. Brain Res 370:1-10.

Arendash GW, Gorski RA (1983) Effects of discrete lesions of the sexually dimorphic nucleus of the preoptic area or other medial preoptic regions on the sexual behavior of male rats. Brain Res Bull 10: $147-150$

Arnold AP, Breedlove SM (1985) Organizational and activational effects of sex steroids on brain and behavior: a reanalysis. Horm Behav 19:469-498.

Arnold AP, Gorski RA (1984) Gonadal steroid induction of structural sex differences in the central nervous system. Annu Rev Neurosci 7: 413-442.

Bailey JM, Pillard RC (1991) A genetic study of male sexual orientation. Arch Gen Psychiatry 48:1089-1096.

Baum MJ, Carroll RS, Cherry JA, Tobet SA (1990) Steroidal control 
of behavioural, neuroendocrine and brain sexual differentiation: studies in a carnivore, the ferret. J Neuroendocrinol 2:401-418.

Beach FA (1971) Hormonal factors controlling the differentiation, development and display of copulatory behavior in the ramstergig and related species. In: Biopsychology of development (Tobach E, Aronson LR, Shaw E, eds), pp 249-296. New York: Academic.

Beato M (1989) Gene regulation by steroid hormones. Cell 56:335344.

Beatty WW (1979) Gonadal hormones and sex differences in nonreproductive behaviors in rodents: organizational and activational influences. Horm Behav 12:112-163.

Bernstein IS, Gordon TP, Ruse RM (1983) The interaction of hormones, behavior, and social context in nonhuman primates. In: Hormones and aggression (Svare B, ed), pp 197-222. New York: Plenum.

Berta P, Hawkins JR, Sinclair AH, Taylor A, Griffiths BL, Goodfellow PN (1990) Genetic evidence equating SRY and the testis-determining factor. Nature 348:448-450.

Bottjer SW, Schoonmaker JN, Arnold AP (1986) Auditory and hormonal stimulation interact to produce neural growth in adult canaries. J Neurobiol 17:605-612.

Bottjer SW, Dignan TP (1988) Joint hormonal and sensory stimulation modulate neuronal number in adult canary brains. J Neurobiol 19 : 624-635.

Breedlove SM (1983) Regional sex differences in steroid accumulation in vertebrate nervous systems. Trends Neurosci 6:403-406.

Breedlove SM (1985) Hormonal control of the anatomical specificity of motoneuron to muscle innervation in rats. Science 227:1357-1359.

Breedlove SM (1986) Cellular analyses of hormone influence on motoneuronal development and function. J Neurobiol 17:157-176.

Breedlove SM, Arnold AP (1980) Hormone accumulation in a sexually dimorphic motor nucleus in the rat spinal cord. Science 210:564 566.

Breedlove SM, Arnold AP (1981) Sexually dimorphic motor nucleus in the rat lumbar spinal cord: response to adult hormone manipulation, absence in androgen-insensitive rats. Brain Res 225:297-307.

Breedlove SM, Arnold AP (1983a) Hormonal control of a developing neuromuscular system: I. Complete demasculinization of the spinal nucleus of the bulbocavernosus in male rats using the anti-androgen flutamide. J Neurosci 3:417-423.

Breedlove SM, Arnold AP (1983b) Hormonal control of a developing neuromuscular system: II. Sensitive periods for the androgen-induced masculinization of the rat spinal nucleus of the bulbocavernosus. $J$ Neurosci 3:424-432.

Brenowitz EA (1991) Altered perception of species-specific song by female birds after lesions of a forebrain nucleus. Science 251:303305.

Brenowitz EA, Arnold AP, Levin RN (1985) Neural correlates of female song in tropical duetting birds. Brain Res 343:104-112.

Buhrich N, Bailey JM, Martin NG (1991) Sexual orientation, sexual identity, and sex-dimorphic behaviors in male twins. Behav Genet 21:75-96.

Bull JJ, Vogt RC (1979) Temperature-dependent sex determination in turtles. Science 206:1186-1188.

Christensen LW, Gorski RA (1978) Independent masculinization of neuroendocrine systems by intracerebral implants of testosterone or estradiol in the neonatal female rat. Brain Res 146:325-340.

Cihak R, Gutmann E, Hanzlikova V (1970) Involution and hormoneinduced persistence of the muscle sphincter (levator) ani in female rats. J Anat 106:93-110.

Clemens LG, Gladue BA, Coniglio LP (1978) Prenatal endogenous androgenic influences on masculine sexual behavior and genital morphology in male and female rats. Horm Rehav 10:40-53.

Crichton-Browne J (1880) On the weight of the brain and its component parts in the insane. Brain $2: 42$.

De Jonge FH, Louwerse AL, Ooms MP, Evers P, Endert E, Van de Poll NE (1989) Lesions of the SDN-POA Inhibit Sexual Behavior of Male Wistar Rats. Brain Res Bull 23:483-492.

Dekaban AS, Sadowsky BS (1978) Changes in brain weights during the span of human life: relation of brain weights to body heights and body weights. Ann Neurol 4:345-356.

DeLacoste M-C, Holloway RL, Woodward DJ (1986) Sex differences in the fetal human corpus callosum. Hum Neurobiol 5:1-5.

DeLacoste-Utamsing C, Holloway RL (1982) Sexual dimorphism in the human corpus callosum. Science 216:1431-1432.

Delville Y (1991) Progesterone-facilitated sexual receptivity: a review of arguments supporting a nongenomic mechanism. Neurosci Biobehav Rev 15:407-414.

DeVoogd T, Nottebohm F (1981) Gonadal hormones induce dendritic growth in the adult avian brain. Science 214:202-204.

De Vries GJ (1989) Review article-sex differences in neurotransmitter systems. I Neuroendocrinol 2:1-13.

Dohler KD, Hines M, Coquelin A, Davis F, Shryne JE, Gorski RA (1982) Pre- and postnatal influence of diethylstilbestrol on differentiation of the sexually dimorphic nucleus in the preoptic area of the female rat brain. Neuroendocrinol Lett 4:361.

Erulkar SD, Wetzel DM (1989) 5Alpha-dihydrotestosterone has nonspecific effects on membrane channels and possible genomic effects on ACh-activated channels. J Neurophysiol 61:1036-1052.

Fischer LM, Kelley DB (1991) Androgen receptor expression and sexual differentiation of effectors for courtship song in Xenopus laevis. Semin Neurosci 3:469-480.

Fishman RB, Breedlove SM (1985) The androgenic induction of spinal sexual dimorphism is independent of supraspinal afferents. Dev Brain Res 23:255-258.

Fishman RB, Breedlove SM (1987) Androgen blockade of bulbocavernosus muscle inhibits testosterone-dependent masculinization of spinal motoneurons in newborn female rats. Soc Neurosci Abstr 13: 1520.

Fishman RB, Breedlove SM (1988) Neonatal androgen maintains sexually dimorphic perineal muscles in the absence of innervation. Muscle Nerve 11:553-560.

Fishman RB, Chism L, Firestone GL, Breedlove SM (1990) Evidence for androgen receptors in sexually dimorphic perineal muscles of neonatal male rats. Absence of androgen accumulation by the perineal motoneurons. J Neurobiol 21:694-705.

Forger NG, Breedlove SM (1986) Sexual dimorphism in human and canine spinal cord: role of early androgen. Proc Natl Acad Sci USA 83:7527-7531.

Forger NG, Breedlove SM (1987a) Motoneuronal death during human fetal development. J Comp Neurol 264:118-122.

Forger NG, Breedlove SM (1987b) Seasonal variation in mammalian striated muscle mass and motoneuron morphology. J Neurobiol 18: 155-165.

Forger NG, Breedlove SM (1991) Steroid influences on a mammalian neuromuscular system. Semin Neurosci 3:459-468.

Gahr M (1990) Delineations of a brain nucleus: comparisons of cytochemical, hodological, and cytoarchitectural views of the song control nucleus HVC of the adult canary. J Comp Neurol 294:30-36.

Gahr M, Konishi M (1988) Developmental changes in estrogen-sensitive neurons in the forebrain of the zebra finch. Proc Natl Acad Sci USA 85:7380-7383.

Goldman S, Nottebohm F (1983) Neuronal production, migration and differentiation in a vocal control nucleus of the adult female canary brain. Proc Natl Acad Sci USA 80:2390-2395.

Gorski RA, Gordon JH, Shryne JE, Southam AM (1978) Evidence for a morphological sex difference within the medial preoptic area of the rat brain. Brain Res 148:333-346.

Grisham W, Kerchner M, Ward IL (1991) Prenatal stress alters sexually dimorphic nuclei in the spinal cord of male rats. Brain Res 551: $126-131$.

Gurney ME (1981) Hormonal control of cell form and number in the zebra finch song system. J Neurosci 1:658-673.

Gurney ME (1982) Behavioral correlates of sexual differentiation in the zehra finch song system. Brain Res 231:153-172.

Gurney ME, Konishi M (1980) Hormone induced sexual differentiation of brain and behavior in zebra finches. Science 208:1380-1382.

Handa RJ, Hines M, Schoonmaker JN, Shryne JE, Gorski RA (1986) Evidence that serotonin is involved in the sexually dimorphic development of the preoptic area in the rat brain. Dev Brain Res 30: 278-282.

Hart BL, Leedy MG (1985) Neurological bases of sexual behavior. A comparative analysis. In: Handbook of behavioral neurobiology, Vol 7, Chap 9 (Adler N, Pfaff D, Goy RW, eds). New York: Plenum.

Hayes KJ (1965) The so-called levator ani of the rat. Acta Endocrinol (Copenh) 48:337-347

Hendricks SE, Gerall AA (1970) Effect of neonatally administered estrogen on development of male and female rats. Endocrinology 87: $435-439$.

Herrmann K, Arnold AP (1991) Lesions of HVc block the develop- 
mental masculinizing effects of estradiol in the female zebra finch song system. J Neurobiol 22:29-39.

Hines M (1982) Prenatal gonadal hormones and sex differences in human behavior. Psychol Bull 92:56-80.

Jacobson CD (1980) The charactcrization, ontogeny and influcnce of androgen on the sexually dimorphic nucleus of the preoptic area. $\mathrm{PhD}$ thesis, University of California at Los Angeles.

Jacobson CD, Gorski RA (1981) Neurogenesis of the sexually dimorphic nucleus of the preoptic area in the rat. J Comp Neurol 196: 519-529.

Jordan CL, Letinsky MS, Arnold AP (1989) The role of gonadal hormones in neuromuscular synapse elimination in rats. I. Androgen delays the loss of multiple innervation in the levator ani muscle. $J$ Neurosci 9:229-238.

Jordan CL, Breedlove SM, Arnold AP (1991) Ontogeny of steroid accumulation in spinal lumbar motoneurons of the rat: implications for androgen's site of action during synapse elimination. J Comp Neurol 312:1-8.

Jordan CL, Pawson PA, Arnold AP, Grinell AD (1992) Hormonal regulation of motor unit size and synaptic strength during synapse elimination in the rat levator ani muscle. J Neurosci 12:4447-4459.

Juraska J (1990) The structure of the rat cerebral cortex: effects of gender and the environment. In: The cerebral cortex of the rat (Kolb B, Tees RC, eds), pp 483-506. Cambridge, MA: MIT Press.

Kelley DB (1988) Sexually dimorphic behavior. Annu Rev Neurosci 11:225-251.

Kelley DB, Dennison J (1990) The vocal motor neurons of Xenopus laevis: development of sex differences in axon number. J Neurobiol $21: 869-882$.

Kelly AJ, Moss RL, Dudley CA, Fawcett CP (1977) The specificity of the response of preoptic-septal area neurons to estrogen: 17alphaestradiol versus 17 beta-estradiol and the response of extrahypothalamic neurons. Exp Brain Res 30:43-52.

Kimura D, Harshman RA (1984) Sex differences in brain organization for verbal and non-verbal functions. Prog Brain Res 61:423-441.

Kirn JR, Nottebohm F (1991) Naturally occurring projection neuron loss in the song control system of the adult canary. Soc Neurosci Abstr 17:876.

Konishi M (1989) Birdsong for neurobiologists. Neuron 3:541-549.

Konishi M, Akutagawa E (1985) Neuronal growth, atrophy and death in a sexually dimorphic song nucleus in the zebra finch brain. Nature 315:145-147.

Konishi M, Akutagawa E (1990) Growth and atrophy of neurons labeled at their birth in a song nucleus of the zebra finch. Proc Natl Acad Sci USA 87:3538-3541.

LeVay S (1991) A difference in hypothalamic structure between heterosexual and homosexual men. Science 253:1034-1037.

Lillie FR (1916) The theory of the freemartin. Science 43:611-613.

Lubischer JL, Jordan CL, Arnold AP (1992) Transient and permanent effects of androgen during synapse elimination in the levator ani muscle of the rat. $J$ Neurobiol 23:1-9.

McGlone J (1980) Sex differences in human brain asymmetry: a critical survey. Behav Brain Sci 3:215-263.

Meisel RL, Ward IL (1981) Fetal female rats are masculinized by male littermates located caudally in the uterus. Science 213:239-242.

Moore CL, Dou H, Juraska JM (1992) Maternal stimulation affects the number of motor neurons in a sexually dimorphic nucleus of the lumbar spinal cord. Brain Res 572:52-56.

Naftolin F, MacLusky N (1984) Aromatization hypothesis revisited. In: Differentiation: basic and clinical aspects (Serio M, ed), pp 169180. New York: Raven.

Nordeen KW, Nordeen EJ (1988) Projection neurons within a vocal motor pathway are born during song learning in zebra finches. Nature 334:149-151.

Nordeen EJ, Nordeen KW (1989) Estrogen stimulates the incorporation of new neurons into avian song nuclei during adolescence. Dev Brain Res 49:27-32.

Nordeen EJ, Nordeen KW, Sengelaub DR, Arnold AP (1985) Androgens prevent normally occurring cell death in a sexually dimorphic spinal nucleus. Science 229:671-673.

Nordeen EJ, Grace A, Burek MJ, Nordeen KW (1992) Sex-dependent loss of projection neurons involved in avian song learning. $J$ Neurobiol, in press.

Nordeen KW, Nordeen EJ, Arnold AP (1987) Estrogen accumulation in zebra finch song control nuclei: implications for sexual differen- tiation and adult activation of song behavior. J Neurobiol 18:569582.

Nottebohm F (1981) A brain for all seasons: cyclical anatomical changes in song control nuclei of the canary brain. Science 214:1368-1370.

Nottcbohm F (1991) Reassessing the mechanisms and origins of vocal learning in birds. Trends Neurosci 14:206-211.

Nottebohm F, Arnold AP (1976) Sexual dimorphism in vocal control areas of the songbird brain. Science 194:211-213.

Nottebohm F, Stokes TM, Leonard CM (1976) Central control of song in the canary Serinus canarius. J Comp Neurol 165:457-486.

Nottebohm F, Alvarez-Buylla A, Cynx J, Kirn J, Ling C-Y, Nottebohm M, Suter R, Tolles A, Williams H (1990) Song learning in birds: the relation between perception and production. Philos Trans $R$ Soc Lond [Biol] 329:115-124.

Okado N, Oppenheim RW (1984) Cell death of motoneurons in the chick embryo spinal cord. IX: The loss of motoneurons following removal of afferent inputs. J Neurosci 4:1639-1652.

Oppenheim JS, Benjamin BS, Lee CP, Nass R, Gazzaniga MS (1987) No sex-related differences in human corpus callosum based on magnetic resonance imagery. Ann Neurol 21:604-606.

Orchinik M, Murray TF, Moore FL (1991) A corticosteroid receptor in neuronal membranes. Science 252:1848-1851.

Paton JA, Nottebohm F (1984) Neurons generated in the adult brain are recruited into functional circuits. Science 225:1046-1048.

Pfaff DW (1966) Morphological changes in the brains of adult male rats after neonatal castration. J Endocrinol 36:415-416.

Phoenix CH, Goy RW, Gerall AA, Young WC (1959) Organizing action of prenatally administered testosterone propionate on the tissues mediating mating behavior in the female guinea pig. Endocrinology 65:369-382.

Purves D (1988) Body and brain. Cambridge, MA: Harvard UP.

Quarmby VE, Yarbrough WG, Lubahn DB, French FS, Wilson EM (1990) Autologous down-regulation of androgen receptor messenger ribonucleic acid. Mol Endocrinol 4:22-28.

Raisman G, Field PM (1973) Sexual dimorphism in the neuropil of the preoptic area of the rat and its dependence on neonatal androgen. Brain Res 54:1-20.

Rand MN, Breedlove SM (1987) Ontogeny of functional innervation of bulbocavernosus muscles in male and female rats. Dev Brain Res 33:150-152.

Sar M, Stumpf WE (1977) Androgen concentration in motor neurons of cranial nerves and spinal cord. Science 197:77-79.

Sassoon DA, Segil N, Kelley DB (1986) Androgen-induced myogenesis and chondrogenesis in the larynx of Xenopus laevis. Dev Biol 113 : $135-140$.

Sassoon DA, Gray GE, Kelley DB (1987) Androgen regulation of muscle fiber type in the sexually dimorphic larynx of Xenopus laevis. J Neurosci 7:3198-3206.

Schlinger BA, Arnold AP (1991a) Androgen effects on the development of the zebra finch song system. Brain Res 561:99-105.

Schlinger BA, Arnold AP (1991b) Brain is the major site of estrogen synthesis in a male songbird. Proc Natl Acad Sci US $\Lambda$ 88:4191-4194.

Schumacher M, Coirini H, Pfaff DW, McEwen BS (1990) Behavioral effects of progesterone associated with rapid modulation of oxytocin receptors. Science 250:691-694.

Sengelaub DR, Arnold AP (1986) Development and loss of early projections in a sexually dimorphic rat spinal nucleus. J Neurosci 6 : 1613-1620.

Simerly RB, Swanson LW, Gorski RA (1984) Demonstration of a sexual dimorphism in the distribution of serotonin-immunoreactive fibers in the medial preoptic nucleus of the rat. J Comp Neurol 225: $151-166$.

Simerly RB, Chang C, Muramatsu M, Swanson LW (1990) Distribution of androgen and estrogen receptor mRNA-containing cells in the rat brain: an in situ hybridization study. J Comp Neurol 294:7695.

Siiteri PK, Wilson JD (1974) Testosterone formation and metabolism during male sexual differentiation in the human embryo. J Clin Endocrinol Metab 38:113-125.

Slimp JC, Hart BL, Goy RW (1975) Heterosexual, autosexual and social behavior of adult male rhesus monkeys with medial preopticanterior hypothalamic lesions. Brain Res 142:105-122.

Swaab DF, Fliers EA (1985) A sexually dimorphic nucleus in the human brain. Science 228:1112-1114. 
Swaab DF, Hofman MA (1984) Sexual differentiation of the human brain. A historical perspective. Prog Brain Res 61:361.

Tobias ML, Kelley DB (1987) Vocalizations by a sexually dimorphic isolated larynx: peripheral constraints on behavioral expression. J Neurosci 7:3191-3197.

Tobin C, Joubert Y (1991) Testosterone-induced development of the rat levator ani muscle. Dev Biol 146:131-138.

Tuller D (1991) Gays divided over brain study. San Francisco Chronicle, Sept 7, p 1.

Vom Saal (1979) Prenatal exposure to androgen influences morphology and aggressive behavior of male and female mice. Horm Behav 12:1-11.

Wada JA, Clarke RA, Hamm A (1975) Cerebral hemisphere asymmetry in humans. Cortical speech zones in 100 adult and 100 infant brains. Arch Neurol 32:239.

Wahli W, Martinez E (1991) Superfamily of steroid nuclear receptors: positive and negative regulators of gene expression. FASEB J 5:22432249.

Ward IL, Weisz J (1980) Maternal stress alters plasma testosterone in fetal males. Science 207:328-329.
Warren DW, Haltmeyer GC, Eik-Nes KB (1973) Testosterone in the fetal rat testis. Biol Reprod 8:560-565.

Watson JT, Kelley DB (1991) Testicular secretions masculinize vocalizations in female $X$. laevis. Soc Neurosci Abstr 17:1058.

Whalen RE, Nadler RD (1963) Suppression of the development of female mating behavior by estrogen administered in infancy. Science 141:273-275.

Wilson JD, George FW, Griffin JE (1981) The hormonal control of sexual development. Science 211:1278-1284.

Witelson SF (1985) The brain connection: the corpus callosum is larger in left-handers. Science 229:665-668.

Yamamoto KR (1985) Steroid receptor regulated transcription of specific genes and gene networks. Annu Rev Genet 19:209-252.

Yarbrough WG, Quarmby VE, Simental JA, Joseph DR, Sar M, Lubahn DB, Olsen KL, French FS, Wilson EM (1990) A single base mutation in the androgen receptor gene causes androgen insensitivity in the testicular feminized rat. J Biol Chem 265:8893-8900.

Yu WA, Srinivasan R (1981) Effect of testosterone and 5 alpha dihydrotestosterone on regeneration of the hypoglossal nerve in rats. Exp Neurol 71:431-435. 